Check for updates

Cite this: RSC Adv., 2018, 8, 40720

Received 26th August 2018

Accepted 23rd November 2018

DOI: $10.1039 / c 8 r a 07113 f$

rsc.li/rsc-advances

\section{Schiff base complex conjugates of bovine serum albumin as artificial metalloenzymes for eco- friendly enantioselective sulfoxidation $\uparrow$}

\author{
Jie Tang, ${ }^{\text {abc }}$ Pengfei Yao, ${ }^{b}$ Lina Wang, ${ }^{b}$ Hedong Bian, (D) *ab Meiyi Luoc \\ and Fuping Huang*b
}

Artificial metalloenzymes (BSA-ML) have been prepared by non-covalent insertion of transition metal Schiffbase complexes, $M L(L=2$-hydroxynaphthalen-1-naphthaldehyde and 3,4-diaminobenzenesulfonic acid; $M$ $=\mathrm{Co}, \mathrm{Mn}, \mathrm{V}, \mathrm{Fe}, \mathrm{Cr}$ ), into bovine serum albumin (BSA) as the host protein and were characterized by UV-visible spectroscopy, ESI-TOF mass spectrometry and molecular docking studies. The catalytic activities of the BSA$\mathrm{ML}$ in the selective oxidation of various prochiral sulfides in aqueous media, using $\mathrm{H}_{2} \mathrm{O}_{2}$ as oxidant, have been evaluated. During the optimization process, $\mathrm{pH}$ and the concentrations of catalyst and oxidant were found to have a remarkable influence on both yield and enantioselectivity. In certain cases, BSA-ML gave satisfactory results in the oxidation of organic sulfides to sulfoxides (up to $100 \%$ conversion, $100 \%$ chemoselectivity, $96 \%$ ee and $500 \mathrm{~h}^{-1}$ turnover frequency).

\section{Introduction}

Asymmetric selective oxidation of sulfides to sulfoxides is an important reaction that deserves much attention because enantiomerically pure sulfoxides are valuable compounds that have utility as powerful chiral auxiliaries,${ }^{1-3}$ ligands,${ }^{4,5}$ organocatalysts $^{6,7}$ in asymmetric organic synthesis, ${ }^{8-10}$ and as active pharmaceutical ingredients. ${ }^{11-15}$ Traditionally, catalysis has been divided into three subdisciplines: heterogeneous, homogeneous, and enzymatic catalysis. Although promising metal catalysts ${ }^{16}$ have been developed and show encouraging practical potential, issues such as compound stability, efficacy, regio- and stereoselectivity, and environmental toxicity remain to be addressed. ${ }^{17}$ Enzymatic activity is reduced by the poor stability of enzymes outside their natural environment. ${ }^{18,19}$ In the past decade, artificial metalloenzymes have emerged as attractive alternatives that complement both homogeneous catalysts and enzymes. ${ }^{20-23}$ Artificial metalloenzymes are hybrid catalysts that incorporate non-natural metal cofactors into biological scaffolds. ${ }^{24-28}$ Compared to their natural counterparts, they are expected to have less complex structures but similar catalytic

${ }^{a}$ School of Chemistry and Chemical Engineering, Guangxi University for Nationalities, Key Laboratory of Chemistry and Engineering of Forest Products, Nanning, 530008, P. R. China. E-mail: gxunchem@163.com

${ }^{b}$ State Key Laboratory for the Chemistry and Molecular Engineering of Medicinal Resources, School of Chemistry and Pharmacy, Guangxi Normal University, Guilin, 541004, P. R. China. E-mail: huangfp2010@163.com

${ }^{c}$ Guilin Normal College, Guilin 541001, P. R. China

$\dagger$ Electronic supplementary information (ESI) available. CCDC 1854581. For ESI and crystallographic data in CIF or other electronic format see DOI: 10.1039/c8ra07113f activity, better solubility in a wide range of solvents and higher stability, especially at high temperatures. ${ }^{29}$

Schiff-bases are a vital class of organic compounds. ${ }^{30}$ Schiff base compounds have been extensively exploited as ligands for mono- or multinuclear macrocyclic or macroacyclic metal complexes, which are useful as biomimetic catalysts ${ }^{31}$ in sulfoxidation. ${ }^{30,32-36}$ In particular, the use of transition metal complexes as catalysts, ${ }^{37}$ mainly based on titanium, ${ }^{38,39}$ vanadium, ${ }^{40,41}$ manganese, ${ }^{42,43}$ and iron, ${ }^{44,45}$ is an area of current interest. ${ }^{46,47}$

Serum albumins, the most abundant blood proteins in mammals, are globular, water-soluble, un-glycosylated transport proteins. ${ }^{48}$ They are not only able to recognize and accept a broad range of substrates, ${ }^{48}$ but can also discriminate between the enantiomers of a chiral molecule. ${ }^{49}$ This makes them promising candidates for the design of artificial metalloenzymes. Gross et al. ${ }^{50}$ embedded bis sulfonated metal corroles containing iron or manganese in to human, bovine, porcine, rabbit and sheep serum albumins. These new "hemozymes" were able to catalyze the sulfoxidation of thioanisole and some analogs in aqueous media. Using hydrogen peroxide as oxidant, sulfoxides were obtained in up to $74 \%$ ee and moderate yield. Bovine serum albumin (BSA) is the most widely used albumin because it is readily available and low cost. ${ }^{51,52}$ However, until very recently, little research has been conducted on the asymmetric oxidation of sulfides catalyzed by artificial metalloenzymes based on BSA.

Increasing global concerns in recent years have led to an exponential increase in the need for economically and environmentally compatible chemical processes. ${ }^{53}$ Consequently, the concept of green chemistry has emerged, which endorses 
the use of environmentally friendly reaction conditions. ${ }^{54}$ Sulfoxidation is generally achieved using oxidizing agents such as $m$-chloroperbenzoic acid, ${ }^{55,56}$ cumene hydroperoxide (CHP), ${ }^{57}$ $\mathrm{NaClO},{ }^{58} \mathrm{NaIO}_{4},{ }^{59}$ oxone, ${ }^{60} \mathrm{KMnO}_{4}$ (ref. 61) and dimethyldioxirane. ${ }^{62}$ Many of these oxidants are known to have undesirable characteristics that include toxicity, formation of by-products, extended reaction times, and low yields. ${ }^{62}$ Reactions that use eco-friendly reagents and solvents such as hydrogen peroxide $\left(\mathrm{H}_{2} \mathrm{O}_{2}\right)$ and water therefore offer great advantages. ${ }^{63-66}$

Inspired by the success of the BSA-cobalt(II) Schiff base complex hybrid that we previously designed as a biocatalyst for asymmetric sulfoxidation, ${ }^{36}$ we have attempted to expand the range of metal cofactors that can be used in the design of artificial metalloenzymes. Using BSA as the biomolecular scaffold, we have explored the application of these new catalysts in the enantioselective oxidation of different sulfides. Beside $\mathrm{Co}(\mathrm{III}), \mathrm{Mn}$ (III) and $\mathrm{Fe}$ (III) complexes we have reported, ${ }^{67}$ in the current, we report the synthesis and characterization of $\mathrm{V}(\mathrm{v})$ and $\mathrm{Cr}$ (III) complexes with a Schiff base ligand derived from 2hydroxynaphthalen-1-naphthaldehyde and 3,4-diaminobenzenesulfonic acid. A series of BSA-ML Schiff base complex hybrids were then designed as biocatalysts. Continuing our efforts to develop simple and green routes, we have accomplished asymmetric sulfoxidation in the presence of water as solvent under mild conditions. Of the designed metalloenzymes, BSA-VL proved to be the most efficient, affording high yield and turnover frequency (TOF) for the conversion of all substrates tested into the corresponding sulfoxides. Up to $94 \%$ enantiomeric purity of 4-methoxyphenyl methyl sulfoxide was achieved.

\section{Experimental section}

\section{Materials}

BSA was purchased from Sigma-Aldrich (St. Louis, MO, USA). All of the sulfides were obtained from Energy Chemical (Shanghai, China). The preparation of 3,4-bis((2-hydroxynaphthalen-1-yl) methyleneamino)benzenesulfonic acid $\left(\mathrm{NaH}_{2} \mathrm{~L}\right)$ has been described previously. ${ }^{67}$ Standard stock solutions $(1 \mathrm{mM})$ of the ML complexes ( $\mathrm{M}=\mathrm{Co}, \mathrm{Mn}, \mathrm{V}, \mathrm{Fe}, \mathrm{Cr})$ and BSA were prepared in dimethyl sulfoxide (DMSO) and $50 \mathrm{mM}$ Tris (trihydroxymethyl aminomethane) buffer solution, $\mathrm{pH}$ 8.0, respectively.

\section{Physical measurements methods}

UV-visible spectra were recorded on a Cary 100 UV-visible spectrophotometer. The FT-IR spectra were recorded on a Perkin-Elmer Spectrum One FT-IR spectrophotometer with a germanium attenuated total reflection (ATR) accessory, a DTGS KBr detector and a $\mathrm{KBr}$ beam splitter ratio. Elemental analyses for $\mathrm{C}, \mathrm{H}$ and $\mathrm{N}$ were carried out on a Model $2400 \mathrm{II}$, Perkin-Elmer elemental analyzer. ESI-MS (electrospray ionization mass spectrum) spectra were recorded on a Bruker HCT Electrospray Ionization Mass Spectrometer. Electrospray ionization-time of flight mass spectrometry (ESI-TOF MS) spectra was measured on an LCQ/AD Quadrupole Ion Trap ESIMS. HPLC experiments were carried out using UV2302II/P2302II high performance liquid chromatograph. Optical rotations were measured with a WXG-4 polarimeter.

\section{Synthesis of the complexes}

All of the complexes were prepared by hydrothermal reaction. The preparations of $\mathbf{M L}(\mathbf{M}=\mathrm{Co}, \mathrm{Mn}, \mathrm{Fe})$ have been described previously. ${ }^{67}$ A mixture of metal salt $\left(0.3 \mathrm{mmol}, \mathrm{V}_{2} \mathrm{O}_{5}\right.$ for $\mathrm{VL}$ and $\mathrm{Cr}\left(\mathrm{NO}_{3}\right)_{3} \cdot 9 \mathrm{H}_{2} \mathrm{O}$ for $\left.\mathrm{CrL}\right), \mathrm{NaH}_{2} \mathrm{~L}(0.3 \mathrm{mmol})$, and methanol (15 $\mathrm{mL}$ ) was placed in a $25 \mathrm{~mL}$ Teflon-lined stainless steel vessel. The reaction mixtures were heated at high temperature $\left(120^{\circ} \mathrm{C}\right.$ for $\mathrm{VL}$ and $80{ }^{\circ} \mathrm{C}$ for $\mathrm{CrL}$ ) for $72 \mathrm{~h}$ and then cooled to room temperature at a controlled rate $\left(10{ }^{\circ} \mathrm{C} \mathrm{h}^{-1}\right.$ for $\mathrm{VL}$ and $5{ }^{\circ} \mathrm{C} \mathrm{h}^{-1}$ for $\mathrm{CrL}$ ). The resulting crystalline products were washed with methanol and dried in air.

Complex VL. Color: atrovirens. Yield: $58 \%$ (based on V(v)). Anal. calc. for $\mathrm{C}_{28} \mathrm{H}_{17} \mathrm{VN}_{2} \mathrm{O}_{6} \mathrm{~S}$ : C, 60.01; H, 3.06; N, 5.00. Found: C, 61.02; H, 3.65; N, 5.14\%. EIS-MS $(m / z):\left[\mathrm{C}_{28} \mathrm{H}_{18} \mathrm{VN}_{2} \mathrm{O}_{6} \mathrm{~S}\right]^{+}$, 561.03. FT-IR (KBr phase, $\mathrm{cm}^{-1}$ ): 3416s, 3135s, $1614 \mathrm{~m}, 1597 \mathrm{~m}$, 1530s, 1357s, 1196s, 1039s, 829m, 751m, 701w, 563w.

Complex CrL. Color: reddish brown. Yield: $48 \%$ (based on $\mathrm{Cr}(\mathrm{III})$ ). Anal. calc. for $\mathrm{C}_{29} \mathrm{H}_{23} \mathrm{CrN}_{2} \mathrm{O}_{7} \mathrm{~S}$ : C,58.48; $\mathrm{H}, 3.89 ; \mathrm{N}, 4.70$. Found: C, 58.28; H, 3.73; N, 4.77\%. EIS-MS (m/z): $\left[\mathrm{C}_{28} \mathrm{H}_{18} \mathrm{CrN}_{2}\right.$ $\left.\mathrm{O}_{5} \mathrm{~S}\right]^{+}, 546.15$. FT-IR (KBr phase, $\mathrm{cm}^{-1}$ ): 3121s, $1615 \mathrm{w}, 1533 \mathrm{~s}$, 1390s, 1357s, 1164s, 1036s, 824m, 752m, 697m.

\section{Crystal structure determination}

X-Ray structure analysis was performed at $293 \mathrm{~K}$ using Agilent Supernova diffractometer (Mo, $\lambda=0.71073 \AA$ ). The structure was collected at 293(2) $\mathrm{K}$ and solved by direct methods using SHELxs-97 (ref. 68) and refined by full-matrix least-squares techniques against $F^{2}$ with SHELxs-97.69 Anisotropic thermal parameters were assigned to all non-hydrogen atoms. The organic hydrogen atoms were generated geometrically, the hydrogen atoms of the water molecules were located from difference maps and refined with isotropic temperature factors. Analytical expressions of neutral-atom scattering factors were employed, and anomalous dispersion corrections were incorporated. The details of the crystal data were summarized in Table 1, and selected bond lengths and angles for complex CrL were listed in Table $\mathrm{S} 1 . \dagger$

\section{Synthesis of hybrids}

The standard stock solution of BSA $(1 \mathrm{~mL})$ was mixed with $\mathrm{ML}$ standard stock solution $(1 \mathrm{~mL})$ and incubated overnight at $0{ }^{\circ} \mathrm{C}$. The mixture was dialyzed ( 3 cycles) in an ice bath, leading to the separation of the protein-complex hybrid from the complex solution. The resulting solution was then purified by sizeexclusion chromatography (Sephadex G-75) and concentrated. The protein concentration was estimated by the Coomassie Brilliant Blue method. ${ }^{\text {7o }}$

\section{Molecular docking}

Docking studies are regarded as a good approach to observe potential binding locations of a drug in a protein. ${ }^{71}$ The docking calculations were performed using AutoDock 4.2 
Table 1 Crystal data and structure refinement for $\mathrm{CrL}$

\begin{tabular}{ll}
\hline Formula & $0.5\left(\mathrm{C}_{58} \mathrm{H}_{40} \mathrm{CrN}_{4} \mathrm{O}_{14} \mathrm{~S}_{2}\right)$ \\
Formula weight & 592.53 \\
Crystal system & Orthorhombic \\
Space group & Pnma \\
$a(\AA)$ & $8.3302(9)$ \\
$b(\AA)$ & $23.634(3)$ \\
$c(\AA)$ & $12.8113(14)$ \\
$\alpha\left({ }^{\circ}\right)$ & $90.00^{\circ}$ \\
$\beta\left(^{\circ}\right)$ & $90.00^{\circ}$
\end{tabular}

$\gamma\left({ }^{\circ}\right)$

$V\left(\AA^{3}\right)$

$Z$

$D_{\mathrm{c}}\left(\mathrm{g} \mathrm{m}^{-3}\right)$

Goodness-of-fit on $F^{2}$

$\theta$ range for data collection $\left(^{\circ}\right)$

Reflections collected/unique

Final $R$ indices $[I>2 \sigma(I)]$

$R$ indices (all data) $90.00^{\circ}$

$2522.2(5)$

4

1.560

1.061

2.9 to $21.3^{\circ}$

$25432 / 2266[R($ int $)=0.069]$

$R_{1}=0.0476 \omega R_{2}=0.1251$

$R_{1}=0.0758 \omega R_{2}=0.1370$ (http://autodock.scripps.edu/, free software), which combines a rapid energy evaluation through pre-calculated grids of affinity potentials with a variety of search algorithms. ${ }^{72}$ The crystal structure of BSA (PDB ID: 3V03) was obtained from the RCSB Protein Data Bank (http://www.rcsb.org/pdb/home/ home.do). All water molecules were removed, and then polar hydrogen atoms were added to the BSA molecule. ${ }^{73}$ The partial atomic charges of BSA and ML were calculated using Gasteiger-Marsili ${ }^{74}$ and Kollman methods, ${ }^{75}$ respectively. The conformational search was selected by using the Lamarckian genetic algorithm (LGA) with the same parameters for each docking. Finally, according to the AutoDock scoring function, the dominating configuration of the BSA-ML with minimum binding energy was obtained..$^{76,77}$ The minimum Gibbs free energy binding mode was visualized in PyMol (http:// www.pymol.org/).

\section{General procedure for enantioselective sulfoxidation}

The catalytic selective oxidation of sulfide was carried out in a glass flask reactor $\left(10 \mathrm{~cm}^{3}\right)$ equipped with a magnetic stirrer and immersed in a thermostated bath. Sulfide $(0.27 \mathrm{mmol})$ and the catalyst, BSA-ML $(2.7 \mu \mathrm{mol})$, were added to $2 \mathrm{~mL}$ of phosphate buffer (PB) solution at $\mathrm{pH}$ 5.1. After stirring for $5 \mathrm{~h}$, the oxidant $\left(\mathrm{H}_{2} \mathrm{O}_{2}, 0.405 \mathrm{mmol}, 30 \% \mathrm{w} / \mathrm{w}\right)$ was added to the solution with stirring. The reaction mixture was stirred for a further $20 \mathrm{~h}$ at ambient temperature $\left(25^{\circ} \mathrm{C}\right)$, and then quenched with sodium sulfite solution. The product and unreacted organic substrates were extracted with dichloromethane $(5 \times 2 \mathrm{~mL})$, dried over anhydrous sodium sulfate and distilled under reduced pressure to remove excess solvent. The crude product was purified by column chromatography on silica gel. Control experiments were carried out under the same reaction conditions but without BSA in the reaction mixture. All of the products obtained in this study are known compounds and their spectroscopic data were identical to those reported in the literature. ${ }^{36}$ The enantiomeric excess (ee) values of the corresponding chiral sulfoxides were determined by HPLC analysis using a chiral column (Daicel, Chiralcel, $\mathrm{OB}-\mathrm{H})$ at room temperature. ee values and chemoselectivity were calculated using the formulas: ee\% $=[$ peak area $(S-R) /(S+R)] \times$ $100 \%$; chemoselectivity $\%=\left[\right.$ peak area $\left.\mathrm{SO} /\left(\mathrm{SO}+\mathrm{SO}_{2}\right)\right] \times 100 \%$, $\mathrm{SO}=$ sulfoxide, $\mathrm{SO}_{2}=$ sulfone. Conversions were based on sulfide substrate; yields were referred to isolated product after column chromatography and were based on substrate; turnover frequencies (TOF) were determined by dividing the concentration of product by the catalyst concentration per hour. The configuration of sulfoxides product from these reactions was proven by comparing the specific rotation with the literature values. ${ }^{36}$

\section{Results and discussion}

\section{Description of the crystal structure}

Single-crystal X-ray structural analysis shows that complex CrL crystallize in space groups of Pnma (Table 1) and the asymmetric unit consists of half a mirror symmetric $\left[\mathrm{CrL}\left(\mathrm{H}_{2}-\right.\right.$ $\left.\mathrm{O})\left(\mathrm{CH}_{3} \mathrm{OH}\right)\right]$ super-molecule. As illustrated in Fig. S1, $\dagger$ The central atom $\mathrm{Cr} 1$ lying on a mirror plane coordinates to two imino nitrogen atom (N1, N1A, symmetry codes: $A x,-y+1 / 2, z)$ with the $\mathrm{Cr}-\mathrm{N}$ distance is 1.991(3) $\AA$, two phenolic oxygen atoms $(\mathrm{O} 6, \mathrm{O} 6 \mathrm{~A})$ from one Schiff base ligand, an water atom $(\mathrm{O} 4)$ and methanol atom (O5) with the $\mathrm{Cr}-\mathrm{O}$ distances fall in the range 1.983(3)-1.994(4) A. to form an distorted octahedral geometry. The adjacent $\left[\mathrm{CrL}\left(\mathrm{H}_{2} \mathrm{O}\right)\left(\mathrm{CH}_{3} \mathrm{OH}\right)\right]$ super-molecules further connect each other through $\mathrm{H}$-bond interactions.

\section{Spectroscopic characterization of the BSA-ML}

The binding interaction between BSA and ML complex was characterized using UV-visible spectroscopy and ESI-TOF mass spectrometry. BSA and BSA-ML hybrid were at equal concentrations and their UV-visible spectra were dominated by a single charge transfer (CT) band in the UV region. The UV-visible spectra of BSA-ML ( $M=\mathrm{Co}, \mathrm{Mn}, \mathrm{Fe})$ have been described previously, ${ }^{67}$ and the spectra of BSA-CrL and BSA-VL are shown in Fig. 1(a) and $\mathrm{S} 2, \uparrow$ respectively. The spectra showed that attachment of CrL to BSA resulted in a shift of $\ddot{e}_{\max }$ from 276 to $272 \mathrm{~nm}$, accompanied by a substantial increase in its intensity, suggesting formation of the BSA-CrL hybrid (Fig. 1(a)). When comparing the CrL complex and BSA-CrL spectra, the presence of BSA induced only a slight shift of the band $(2 \mathrm{~nm})$ in the UV region, together with a slight increase in its intensity. For further analysis of the interaction between CrL and BSA, the ESITOF mass spectrum was recorded (Fig. 1(b)). The mass spectrum of a mixture of CrL complex and BSA gave two peaks, one of which corresponded to the calculated mass of the BSA-CrL hybrid $(\mathrm{m} / \mathrm{z}$ 66961), in which 1 equiv. of the catalyst was attached to BSA $(\mathrm{m} / \mathrm{z}$ 66416), indicating successful anchoring. ${ }^{78,79}$ The ESI-TOF spectra of the other four complexes are shown in the ESI (Fig. S3†). 

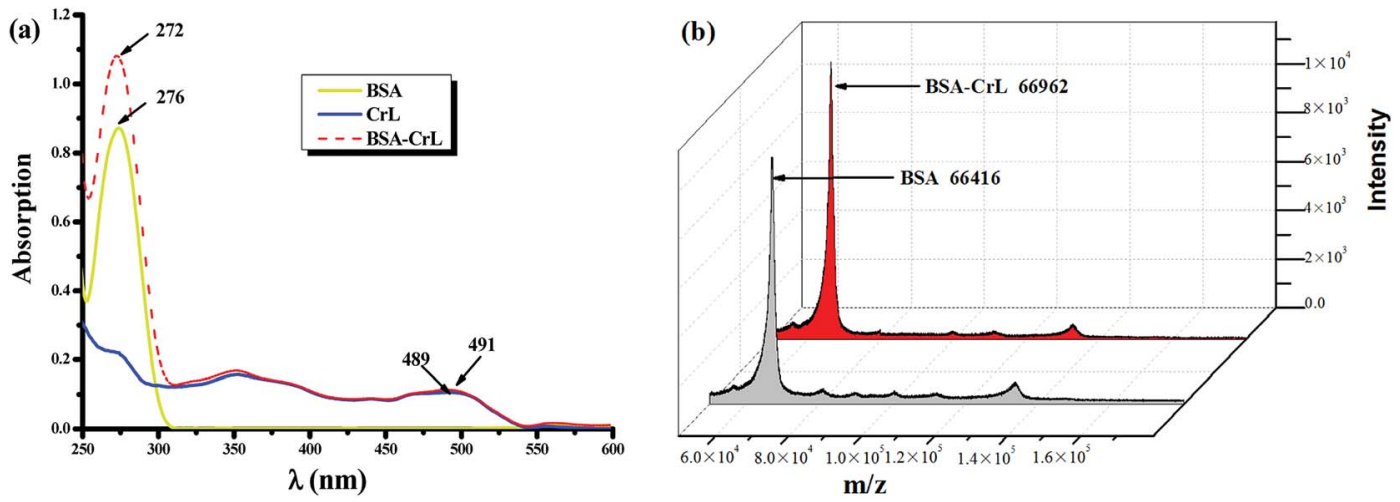

Fig. 1 (a) UV-visible spectra of $20 \mathrm{iM} \mathrm{BSA}$ (yellow solid line), $20 \mathrm{iM} \mathrm{CrL} \mathrm{complex} \mathrm{(blue} \mathrm{solid} \mathrm{line)} \mathrm{and} 20 \mathrm{iM}$ BSA-CrL hybrid (red dashed line) in 0.05 M PBS buffer pH 7.45; (b) ESI-TOF MS spectrum of BSA and BSA-CrL.

\section{Molecular docking studies}

Molecular docking has become a useful tool in recent years for understanding the binding interactions between synthesized compounds and biological macromolecules. To explore the potential binding site of CrL complex on BSA, a molecular docking study was performed. BSA is a globular protein composed of three homologous domains (I, II, III), each of which is divided into subdomains $\mathrm{A}$ and $\mathrm{B} .^{\mathbf{8 0 , 8 1}}$ Fig. 2(a) shows the lowest energy binding mode found for CrL binding to BSA. Similarly to artificial metalloenzymes that we have reported previously, ${ }^{36}$ the binding site of CrL was located in subdomain IB (site I), which contains a hydrophobic, polar environment. A close-up view of this docked form is shown in Fig. 2(b). The amino acid residues closest to the ligand, including Glu-125, Lys-136 and Thr-121 etc., suggest hydrophobic and van der Waals interactions to the compound, ${ }^{82,83}$ consistent with the spectroscopic data.

\section{Catalytic activity in asymmetric sulfoxidation}

Initially, the oxidation reactions were carried out with thioanisole as a model substrate and $\mathrm{H}_{2} \mathrm{O}_{2}$ as oxidant in water at room temperature $\left(25{ }^{\circ} \mathrm{C}\right)$. The value of the hybrid was demonstrated by comparing the catalytic properties of ML with the BSA-ML hybrid. The results are presented in Table 2. When experiments were run in the absence of BSA, the reactions proceeded with low chemoselectivity and almost zero enantioselectivity (entries 1-5). In contrast, when the reaction was run in the presence of BSA-ML as catalyst, the ee values increased

Table 2 Enantioselective oxidation of thioanisole ${ }^{a}$

Entry Catalyst Conversion (\%) Yield (\%) Chemoselectivity (\%) ee (\%)

$\begin{array}{lllrrl}1 & \text { CoL } & 65 & 41 & 64 & <5 \\ 2 & \text { MnL } & 54 & 39 & 72 & <5 \\ 3 & \text { VL } & 62 & 40 & 65 & <5 \\ 4 & \text { FeL } & 66 & 50 & 77 & <5 \\ 5 & \text { CrL } & 59 & 44 & 75 & <5 \\ 6 & \text { BSA-CoL } & 88 & 88 & 100 & 31 \\ 7 & \text { BSA-MnL } & 70 & 70 & 100 & 32 \\ 8 & \text { BSA-VL } & 86 & 81 & 95 & 27 \\ 9 & \text { BSA-FeL } & 90 & 90 & 100 & 16 \\ 10 & \text { BSA-CrL } & 79 & 77 & 98 & 15\end{array}$

${ }^{a}$ Reactions were performed in $\mathrm{PB}(2 \mathrm{~mL}, \mathrm{pH} 5.1)$ at room temperature for $20 \mathrm{~h}$. The ratios of $\mathrm{H}_{2} \mathrm{O}_{2}$ : thioanisole : catalyst $(2.7 \mu \mathrm{mol})$ were $150: 100: 1$. The sulfoxide of thioanisole was in the $R$ configuration.
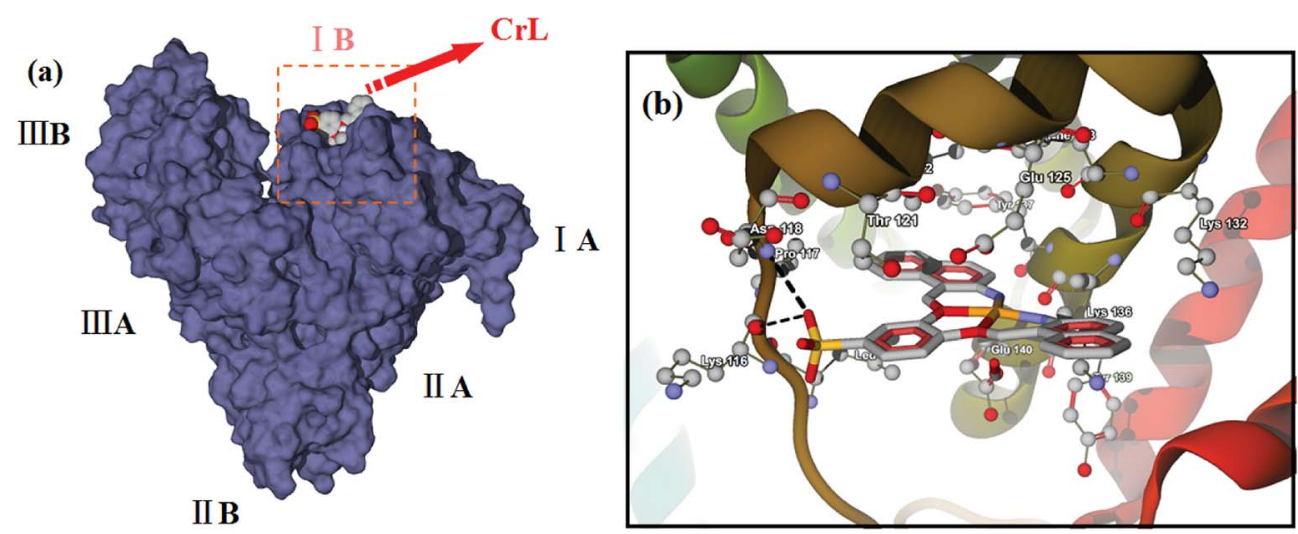

Fig. 2 (a) Is the lowest energy binding mode of CrL to BSA; (b) is the close-up view of binding site of CrL on BSA corresponding to (a), and the selected amino acid residues are shown by stick model. 
significantly (entries 6-10) and thioanisole sulfoxide was obtained as the major product with high chemoselectivity (95$100 \%)$. These results strongly suggest that the BSA scaffold enhances both the reactivity and enantioselectivity of metal catalysts. The protein scaffold provides a hydrophobic pocket that may favor collision with substrate. ${ }^{\mathbf{8 4}}$ Similarly, many reports ${ }^{\mathbf{3 6}, \mathbf{8 5}-\mathbf{8 8}}$ have found that the host protein has an influence on reactivity and enantioselectivity.

\section{Influence of $\mathbf{p H}$}

The optimal reaction conditions were determined by conducting reactions at different $\mathrm{pH}$ values, as well as various substrate, oxidant and catalyst concentrations. Firstly, the effect of $\mathrm{pH}$ values was determined in $\mathrm{PB}(\mathrm{pH}$ 4.7-9) at room temperature and the results are shown in Fig. 3. The $\mathrm{pH}$ of the reaction medium had a highly significant effect on the activity of BSA-ML $(\mathrm{M}=\mathrm{Co}, \mathrm{Mn}, \mathrm{Cr})$ and $e e$ in the oxidation of thioanisole. In the case of BSA-FeL, the $\mathrm{pH}$ value did not have a significant effect. In particular, the chemoselectivity was high (95-100\%, Fig. 3(a)). Optimal chemoselectivities, yields and ee values were obtained at more acidic $\mathrm{pH}$ values with BSA-ML $(\mathrm{M}=\mathrm{Co}, \mathrm{Mn}$, $\mathrm{Cr}$ ), while the highest values with BSA-VL and BSA-FeL were obtained at non-acidic $\mathrm{pH}$ values under the same reaction conditions (Fig. 3(a)-(c)). The BSA-ML ( $\mathrm{M}=\mathrm{Co}, \mathrm{Mn}, \mathrm{Cr}$ ) complexes would be easily decomposed under extreme $\mathrm{pH}$ conditions, which limits the available range under basic conditions. Different $\mathrm{pH}$ values were selected depending on the optimum enantioselectivity ( $\mathrm{pH} 6$ for BSA-CoL and BSA-CrL, $\mathrm{pH}$ 5.1 for BSA-MnL, and $\mathrm{pH} 8$ for BSA-VL and BSA-FeL) (Fig. 3(c)).

\section{Influence of substrate concentration}

Full details are presented in Table 3. Overall, changes to the substrate concentration did not increase catalytic activity or the ee value. Good chemoselectivities $(\geq 90 \%)$ were obtained when the thioanisole concentration was increased over the range of 0.034-0.338 mM. However, the clearest difference was observed with BSA-MnL (Table 3, entries 7-12). Higher concentrations of thioanisole reduced the yield and ee values, with almost no changes in the sulfoxide selectivity $(>95 \%)$. The ee values increased significantly from $8 \%$ to $32 \%$ when the substrate concentration was increased from 0.034 to $0.135 \mathrm{mM}$. Accordingly, $0.068 \mathrm{mM}$ (for BSA-CoL), $0.135 \mathrm{mM}$ (for BSA-MnL and BSA-CrL) and $0.203 \mathrm{mM}$ (for BSA-VL and BSA-FeL) were chosen as the optimum concentrations for further experiments (Table 3 , note numbers in bold).

\section{Influence of oxidant and catalyst concentrations}

Having optimized the $\mathrm{pH}$ and substrate concentration for the oxidation of thioanisole, we next examined the effect of $\mathrm{H}_{2} \mathrm{O}_{2}$ and catalyst stoichiometry (with respect to substrate) on the conversion, selectivity and ee of the product (Tables 4 and 5). It was evident for all complexes except BSA-CrL that a greater amount of $\mathrm{H}_{2} \mathrm{O}_{2}$ increased conversion during $20 \mathrm{~h}$, but decreased product selectivity by giving the over-oxidized sulfone
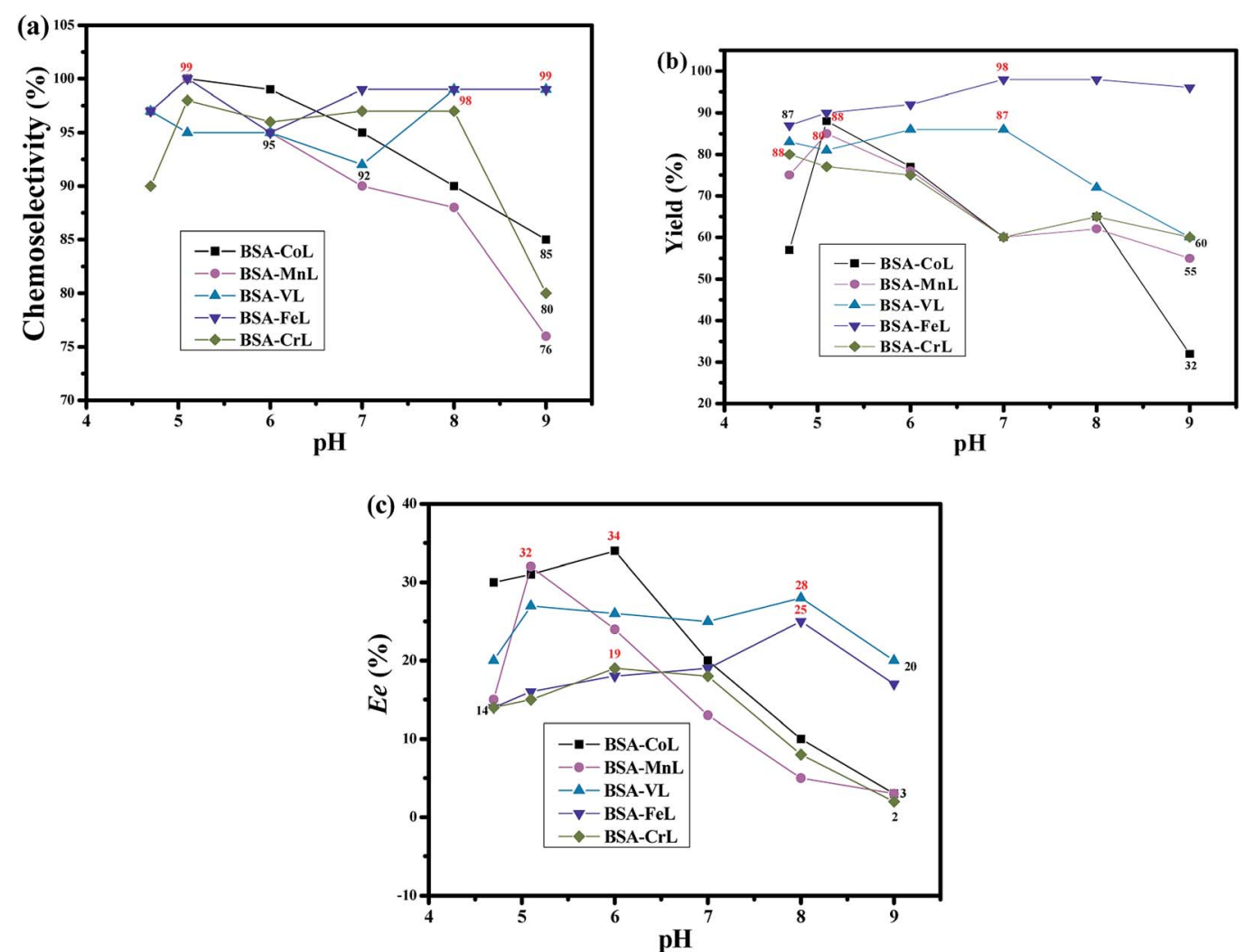

Fig. 3 (a) Chemoselectivity, (b) yield and (c) ee values under different $\mathrm{pH}$ values on the oxidation of thioanisole in $\mathrm{PB}$ at room temperature for 20 h. The mol ratios of $\mathrm{H}_{2} \mathrm{O}_{2}$ : thioanisole : BSA-ML (2.7 $\left.\mu \mathrm{mol}\right)$ were $150: 100: 1$. The sulfoxide of thioanisole was in the $R$ configuration. 
Table 3 Effect of substrate concentration on the oxidation of thioanisole ${ }^{a}$

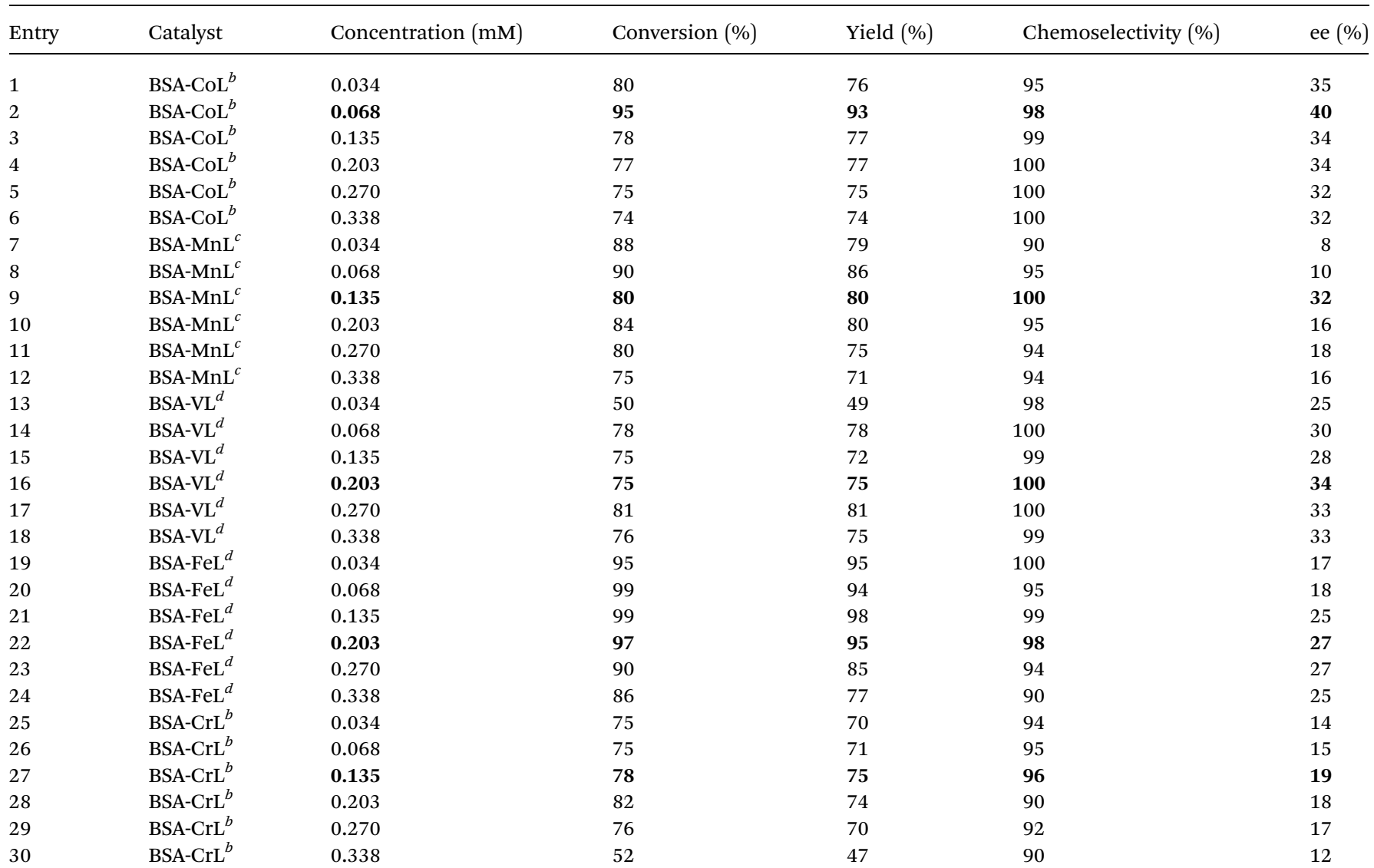

${ }^{a}$ Reactions were performed in $\mathrm{PB}(2 \mathrm{~mL})$ at room temperature for $20 \mathrm{~h}$. The ratios of $\mathrm{H}_{2} \mathrm{O}_{2}:$ thioanisole: BSA-ML were $150: 100: 1 .{ }^{b} \mathrm{pH}=6 .{ }^{c} \mathrm{pH}=$ 5.1. ${ }^{d} \mathrm{pH}=8$; the sulfoxide of thioanisole was in the $R$ configuration.

product in excess. There was little change in the ee of the desired product. In the case BSA-CrL, increasing the oxidant concentration from 1 to 2.5 equivalents reduced conversion and selectivity, but increased the enantiomeric excess (Table 4, entries 17-20). Similar to the artificial enzyme that we reported previously, this effect may be due to oxidative destruction of the catalyst, BSA-CrL, combined with a kinetic resolution process due to excess oxidant. ${ }^{36}$ Systematic variation of the oxidant: substrate molar ratio revealed the best compromise between catalytic activity and sulfoxide ee value (Table 4 , note numbers in bold).

The concentration of catalyst is an important factor, as previously reported by H. R. Khavasi et al. ${ }^{89}$ For all catalysts, the conversion of thioanisole increased when the proportion of catalyst was increased from $0.5 \mathrm{~mol} \%$ to $1 \mathrm{~mol} \%$ of substrate. A higher concentration of catalyst reduced conversion and ee value with almost no changes in sulfoxide selectivity $(>89 \%)$ (Table 5). The optimal amount of catalyst can be explained considering the reports of Marchena et al., ${ }^{\mathbf{9 0}}$ who indicated that the $\mathrm{H}_{2} \mathrm{O}_{2}$ decomposition rate increased at higher catalyst loading. The lower availability of oxidant explains the decreased conversion when the catalyst loading is increased. A catalyst loading of $1 \mathrm{~mol} \%$ of substrate was therefore selected.

\section{Scope of catalysis}

After optimization of the reaction conditions, we successfully oxidized a variety of sulfides using hybrid BSA-ML as the catalyst (Scheme 1).

As shown in Table S2, $\uparrow$ the ML complex did not greatly affect the chemoselectivity for all substrates. In $92 \%$ of cases, chemoselectivities of $\geq 90 \%$ were obtained with BSA-ML hybrids. As in natural metalloenzymes, the role of the BSA scaffold is to drive the selectivity and protect the inorganic catalyst. The cavity may release the reaction product, sulfoxide, before it is over-oxidized into sulfone, leading to the observed high selectivity. ${ }^{91}$ In particular, good chemoselectivities were achieved even for sulfides with branched or longer alkyl groups instead of aryl substituents (substrates 11-13). Throughout the series of substrates, the results indicated a considerable effect on three important aspects: enantioselectivity, chemical yield and TOF. The ee values for all substrates averaged $31.9 \%, 8.8 \%, 29.0 \%$, $15.8 \%$, and $7.5 \%$ for conjugates of BSA with CoL, MnL, VL, FeL and CrL, respectively. A similar effect was observed for the yield of sulfoxide, but the average values were significantly higher: $63.7 \%, 68.8 \%, 91.6 \%, 85.8 \%$ and $62.1 \%$. Compared to BSA-CoL/ $\mathrm{MnL} / \mathrm{CrL}$ (average TOFs $<350 \mathrm{~h}^{-1}$ ), BSA-VL and BSA-FeL afforded good TOFs (average values of $454 \mathrm{~h}^{-1}$ and $429 \mathrm{~h}^{-1}$, 
Table 4 Effect of oxidant concentration on the oxidation of thioanisole ${ }^{a}$

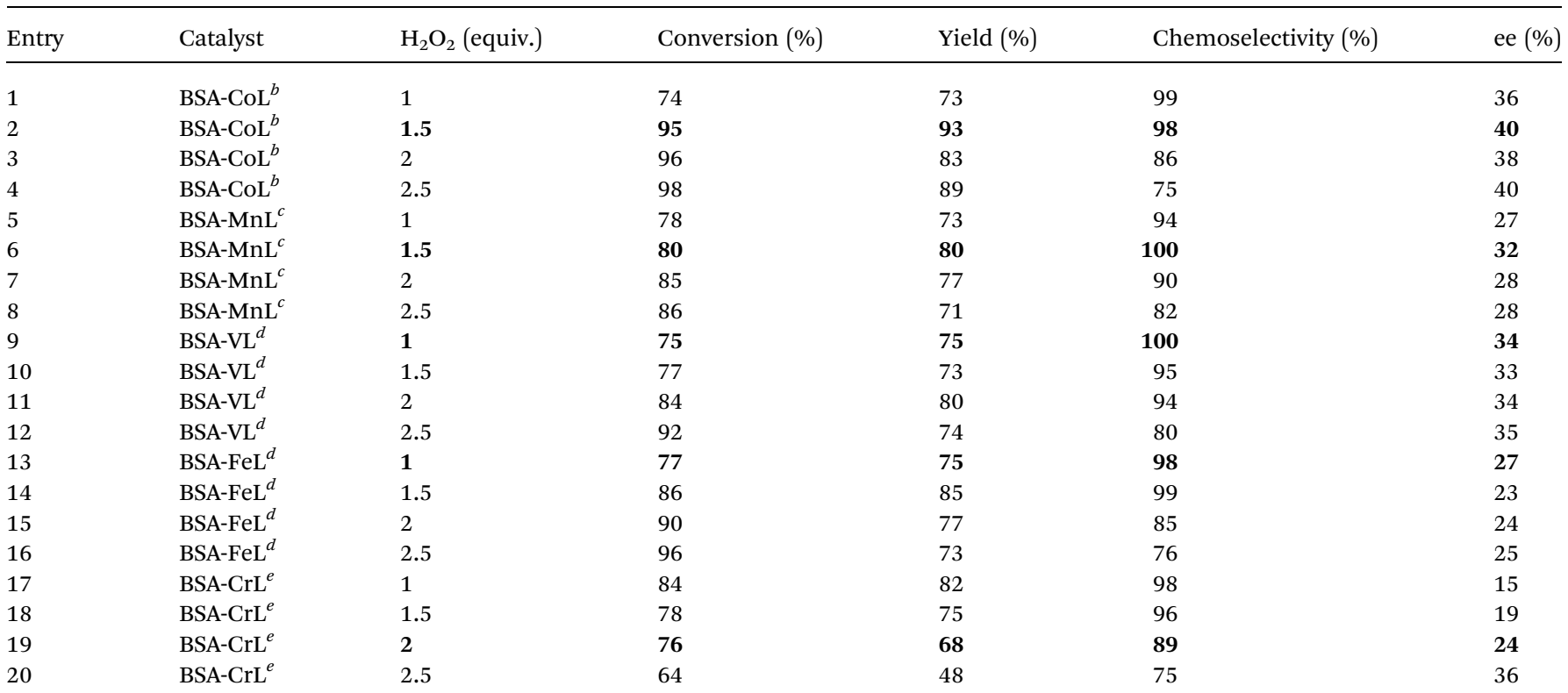

${ }^{a}$ Reactions were performed in PB $(2 \mathrm{~mL})$ at room temperature for $20 \mathrm{~h}$; The ratio of thioanisole : BSA-ML was $100: 1 .^{b} \mathrm{pH}=6$; the concentration of thioanisole was $0.068 \mathrm{mM}^{c}{ }^{c} \mathrm{pH}=5.1$; the concentration of thioanisole was $0.135 \mathrm{mM} .^{d} \mathrm{pH}=8$; the concentration of thioanisole was 0.203 mM. ${ }^{e} \mathrm{pH}=6$; the concentration of thioanisole was $0.135 \mathrm{mM}$. The sulfoxide of thioanisole was in the $R$ configuration.

respectively, Fig. 4(a)). Pleasingly, under certain reaction conditions BSA-VL/FeL/CrL completely and selectively provided the appropriate sulfoxide within $20 \mathrm{~h}$ with high TOFs (BSA-VL for sulfides 3 and 5; BSA-FeL for sulfide 7; BSA-CrL for sulfide
5) (Table S2, $\uparrow$ note the marks in bold). Another aspect of the metal effect was that the identity of the major enantiomer obtained with BSA conjugated to different ML was frequently opposite (e.g., BSA-CoL/VL (R) vs. BSA-FeL (S) for substrate 7;

Table 5 Effect of catalyst concentration on the oxidation of thioanisole ${ }^{a}$

\begin{tabular}{|c|c|c|c|c|c|c|}
\hline Entry & Catalyst & Concentration $(\mu \mathrm{M})$ & Conversion (\%) & Yield (\%) & Chemoselectivity (\%) & ee $(\%)$ \\
\hline 1 & BSA-CoL ${ }^{b}$ & 0.34 & 84 & 83 & 99 & 32 \\
\hline 2 & $\mathrm{BSA}^{-\mathrm{CoL}^{b}}$ & 0.68 & 95 & 93 & 98 & 40 \\
\hline 3 & BSA-CoL ${ }^{b}$ & 1.02 & 92 & 87 & 95 & 35 \\
\hline 4 & $\mathrm{BSA}^{-\mathrm{CoL}^{b}}$ & 1.36 & 88 & 84 & 96 & 36 \\
\hline 5 & BSA-MnL $^{c}$ & 0.68 & 68 & 65 & 96 & 30 \\
\hline 6 & BSA-MnL ${ }^{c}$ & 1.35 & 80 & 80 & 100 & 32 \\
\hline 7 & BSA-MnL ${ }^{c}$ & 2.03 & 75 & 71 & 95 & 30 \\
\hline 8 & BSA-MnL ${ }^{c}$ & 2.70 & 66 & 61 & 92 & 26 \\
\hline 9 & $\mathrm{BSA}^{-\mathrm{VL}^{d}}$ & 1.02 & 70 & 70 & 100 & 30 \\
\hline 10 & $\mathrm{BSA}^{-\mathrm{VL}^{d}}$ & 2.03 & 75 & 75 & 100 & 34 \\
\hline 11 & $\mathrm{BSA}^{-\mathrm{VL}^{d}}$ & 3.05 & 74 & 70 & 94 & 32 \\
\hline 12 & $\mathrm{BSA}-\mathrm{VL}^{d}$ & 4.06 & 55 & 52 & 95 & 28 \\
\hline 13 & BSA-FeL ${ }^{d}$ & 1.02 & 65 & 64 & 98 & 24 \\
\hline 14 & BSA-FeL ${ }^{d}$ & 2.03 & 77 & 75 & 98 & 27 \\
\hline 15 & BSA-FeL ${ }^{d}$ & 3.05 & 70 & 67 & 95 & 23 \\
\hline 16 & BSA-FeL ${ }^{d}$ & 4.06 & 59 & 57 & 96 & 23 \\
\hline 17 & $\mathrm{BSA}-\mathrm{CrL}^{e}$ & 0.68 & 74 & 68 & 92 & 15 \\
\hline 18 & $\mathrm{BSA}-\mathrm{CrL}^{e}$ & 1.35 & 76 & 68 & 89 & 24 \\
\hline 19 & $\mathrm{BSA}^{-\mathrm{CrL}}{ }^{e}$ & 2.03 & 66 & 59 & 90 & 24 \\
\hline 20 & BSA-CrL ${ }^{e}$ & 2.70 & 64 & 58 & 91 & 20 \\
\hline
\end{tabular}

${ }^{a}$ Reactions were performed in $\mathrm{PB}(2 \mathrm{~mL})$ at room temperature for $20 \mathrm{~h} .{ }^{b} \mathrm{pH}=6$; the ratio of $\mathrm{H}_{2} \mathrm{O}_{2}:$ thioanisole $(0.068 \mathrm{mM})$ was $150: 100 .^{c} \mathrm{pH}=$ 5.1; the ratio of $\mathrm{H}_{2} \mathrm{O}_{2}$ : thioanisole $(0.135 \mathrm{mM})$ was $150: 100 .{ }^{d} \mathrm{pH}=8$; the ratio of $\mathrm{H}_{2} \mathrm{O}_{2}$ : thioanisole $(0.203 \mathrm{mM})$ was $100: 100$. ${ }^{e} \mathrm{pH}=6$; the ratio of $\mathrm{H}_{2} \mathrm{O}_{2}$ : thioanisole $(0.135 \mathrm{mM})$ was $200: 100$. The sulfoxide of thioanisole was in the $R$ configuration. 


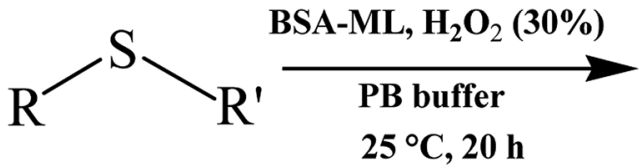

$25^{\circ} \mathrm{C}, 20 \mathrm{~h}$
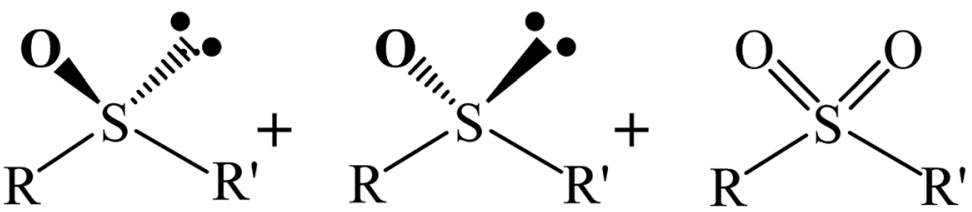
$1 \mathrm{R}=\mathrm{Ph}$
$\mathrm{R}^{\prime}=\mathrm{Me}$
$5 \mathrm{R}=p-\mathrm{ClPh}$
$\mathrm{R}^{\prime}=\mathrm{Me}$
$9 \mathrm{R}=\mathrm{Ph}$
$\mathrm{R}^{\prime}=\mathrm{CH}_{2} \mathrm{CH}$
$2 \mathrm{R}=o-\mathrm{ClPh} \quad \mathrm{R}^{\prime}=\mathrm{Me}$
$6 \mathrm{R}=p-\mathrm{BrPh}$
$\mathrm{R}^{\prime}=\mathrm{Me}$
$10 \mathrm{R}=\mathrm{PhCH}_{2}$
$\mathrm{R}^{\prime}=\mathrm{Me}$
$3 \mathrm{R}=m-\mathrm{ClPh} \quad \mathrm{R}^{\prime}=\mathrm{Me}$
$7 \mathrm{R}=p-\mathrm{MePh}$
$\mathrm{R}^{\prime}=\mathrm{Me}$
$11 \mathrm{R}=t$-Bu
$\mathrm{R}^{\prime}=\mathrm{Me}$
$4 \mathrm{R}=m-\mathrm{BrPh} \quad \mathrm{R}^{\prime}=\mathrm{Me}$
$8 \mathrm{R}=p-\mathrm{MeOPh}$
$\mathrm{R}^{\prime}=\mathrm{Me}$
$12 \mathrm{R}=$ octane $\mathrm{R}^{\prime}=\mathrm{Me}$
$13 \mathrm{R}=\mathrm{n}$-dodecyl $\mathrm{R}^{\prime}=\mathrm{Me}$

Scheme 1 Enantioselectivity of various prochiral sulfides oxidation using BSA-ML as the catalyst.
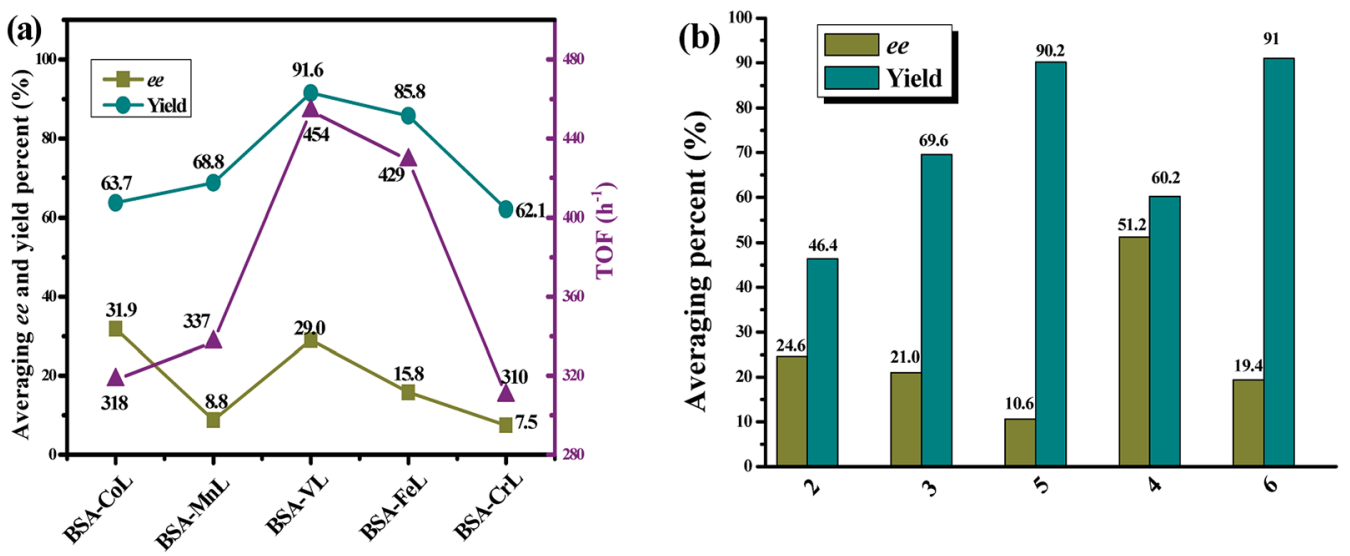

Fig. 4 (a) Comparison of averaging ee values (dark yellow), averaging yields (dark cyan) and turnover frequencies (purple) in the sulfoxidation reactions catalyzed by BSA-ML; (b) comparison of averaging ee values (dark yellow), averaging yields (dark cyan) in the sulfoxidation for different substrates. Reactions were performed in the optimal reaction conditions for different BSA-ML system.

BSA-FeL (S) vs. BSA-VL/MnL/CrL (R) for substrate 8; BSA-CoL/ FeL (R) vs. BSA-MnL/CrL (S) for substrate 9; BSA-CoL (R) vs. BSA-VL/FeL (S) for substrate 12) (Table $\mathrm{S} 2, \uparrow$ note the red marks).

The data in Table $\mathrm{S} 2 \dagger$ also suggest that both steric and electronic factors have a pronounced effect on the enantioselectivity of the reaction. The average ee obtained for all BSA-ML with substrates 2,3 and 5 were $24.6 \%, 21.0 \%$ and $10.6 \%$, respectively. Similarly, the products from the oxidation of substrates 4 and 6 were obtained with ee values of $51.2 \%$ and 19.4\%, respectively (Fig. 4(b)). The results indicated that increasing the steric bulk of the aromatic moiety of the sulfide led to an increase in enantioselectivity. This is consistent with the results obtained with the artificial metalloenzyme reported previously. ${ }^{36}$ In contrast, a lower yield was observed (Fig. 4(b)). In addition, it is note worthy that disappointing enantiomeric excesses $(<25 \%$, except for BSA-CoL with sulfide 10) were obtained with sterically bulky sulfides (sulfides 9-10) and those with branched or longer alkyl groups instead of aryl substituents (sulfides 11-13) (Table S2 $\dagger$ ), while the yields were moderate to high (average $\mathbf{4 5 . 8 - 9 2 . 8 \%}$ for sulfides 9-13). Sulfides containing electron-donating Me (sulfide 7) and OMe (sulfide 8) at the para position on the phenyl gave sulfoxides with much lower enantioselectivity (average 6.7\%, except for BSA-VL with sulfide 8) and higher yield (average 93.2\%) than those observed for thioanisole (average $31.4 \%$ ee and $78.2 \%$ yield) with all BSA-ML. Interestingly, the introduction of electron-withdrawing $\mathrm{Cl}$ (sulfide 5) and $\mathrm{Br}$ (sulfide 6) groups at the para position resulted in a similar effect, both of which gave relatively lower average ee $(15.0 \%)$ and higher average yield (95.2\%). Similarly, higher TOFs $\left(>400 \mathrm{~h}^{-1}\right.$, except for BSA-CoL with sulfide 5) were obtained for the sulfoxidation of substrates with electrondonating or electron-with drawing groups on the phenyl and consequently more easily oxidized. This suggests that the effect of substrate is predominantly steric rather than electronic.

\section{Conclusions}

In summary, we have successfully synthesized and characterized five artificial metalloenzymes consisting of a ML cofactor bound to BSA. All of the prepared BSA-ML tested in this study showed catalytic activity for sulfide oxidation under environmentally friendly and mild conditions (using $\mathrm{H}_{2} \mathrm{O}_{2}$ as the 
oxidant) in aqueous media. This study may drive further research into the use of BSA, a cheap an abundant protein, in oxidation reactions. More significantly, the mild reaction conditions make the present protocol very useful to address environmental concerns and the industrial need for green, sustainable chemistry. The $\mathrm{pH}$ and concentrations of catalyst and oxidant were varied to improve conversion, selectivity and enantioselectivity for thioanisole. In the oxidation of different sulfides, the observed activity depended mainly on the nature of the ML and substrates. The highest catalytic activity was obtained with BSA-VL, which gave satisfactory catalytic activity in certain cases (yield, ee and TOF up to $100 \%, 96 \%$ and $500 \mathrm{~h}^{-1}$, respectively). The next steps will be to develop immobilization strategies that may contribute to the stability of artificial enzymes, while allowing then to be recycled.

\section{Conflicts of interest}

There are no conflicts to declare.

\section{Acknowledgements}

We gratefully acknowledge the National Natural Science Foundation of China $(21361003,21861005)$, the Natural science Foundation of Guangxi (2016GXNSFDA380005, 2016GXNSFFA380010, 2016GXNSFBA380237), Middle-aged and young teachers in colleges and universities in Guangxi basic ability promotion project (KY2016LX480), New Century Ten, Hundred, Thousand Talents Project in Guangxi, The Innovative Team \& Outstanding Talent Program of Colleges and Universities in Guangxi (2017-38) and the Foundation of Key Laboratory for Chemistry and Molecular Engineering of Medicinal Resources, IRT 1225.

\section{References}

1 Z.-H. Zhang, X.-S. Yang, Q.-Q. Zhang, L. Wang, M.-Y. He, Q. Chen and X.-F. Huang, RSC Adv., 2016, 6, 104036-104040.

2 S. Otocka, M. Kwiatkowska, L. Madalińska and P. Kiełbasiński, Chem. Rev., 2017, 117, 4147-4181.

3 H. Gholami, J. Zhang, M. Anyika and B. Borhan, Org. Lett., 2017, 19, 1722-1725.

4 M. Mellah, A. Voituriez and E. Schulz, Chem. Rev., 2007, 107, 5133-5209.

5 S. M. G. Pires, M. M. Q. Simões, I. C. M. S. Santos, S. L. H. Rebelo, M. M. Pereira, M. G. P. M. S. Neves and J. A. S. Cavaleiro, Appl. Catal., A, 2012, 439-440, 51-56.

6 A. Massa, A. V. Malkov, P. Kocovsky and A. Scettri, Tetrahedron Lett., 2003, 44, 7179-7181.

7 S. Kobayashi, C. Ogawa, H. Konishi and M. Sugiura, J. Am. Chem. Soc., 2003, 125, 6610-6611.

8 J. Legros, J. R. Dehli and C. Bolm, Adv. Synth. Catal., 2005, 347, 19-31.

9 S. Doherty, J. G. Knight, M. A. Carroll, A. R. Clemmet, J. R. Ellison, T. Backhouse, N. Holmes, L. A. Thompson and R. A. Bourne, RSC Adv., 2016, 6, 73118-73131.
10 Y.-Y. Zhang, R. Tan, G.-W. Zhao, X.-F. Luo, C. Xing and D.-H. Yin, J. Catal., 2016, 335, 62-71.

11 S. Rodríguez, N. Haddad, R. P. Frutos, N. Grinberg, D. Krishnamurthy and C. H. Senanayake, Org. Process Res. Dev., 2017, 21, 444-447.

12 P. K. Bera, P. Kumari, S. H. R. Abdi, N. H. Khan, R. I. Kureshy, P. S. Subramanianab and H. C. Bajaj, RSC Adv., 2014, 4, 61550-61556.

13 D. Linde, M. Cañellas, C. Coscolín, I. Davó-Siguero, A. Romero, F. Lucas, F. J. Ruiz-Dueñas, V. Guallar and A. T. Martínez, Catal. Sci. Technol., 2016, 6, 6277-6285.

14 C. J. Carrasco, F. Montilla and A. Galindo, Catal. Commun., 2016, 84, 134-136.

15 C. Shen, J. Qiao, L.-W. Zhao, K. Zheng, J.-Z. Jin and P.-F. Zhang, Catal. Commun., 2017, 92, 114-118.

16 J. Fujisaki, K. Matsumoto, K. Matsumoto and T. Katsuki, J. Am. Chem. Soc., 2011, 133, 56-61.

17 C. Herrero, N. Nguyen-Thi, F. Hammerer, F. Banse, D. Gagné, N. Doucet, J.-P. Mahy and R. Ricoux, Catalysts, 2016, 6, 202-214.

18 L. Rondot, E. Girgenti, F. Oddon, C. Marchi-Delapierre, A. Jorge-Robin and S. Ménage, J. Mol. Catal. A: Chem., 2016, 416, 20-28.

19 V. Mojr, M. Buděšínský, R. Cibulka and T. Kraus, Org. Biomol. Chem., 2011, 9, 7318-7326.

20 T. Heinisch and T. R. Ward, Acc. Chem. Res., 2016, 49, 17111721.

21 Y. Okamoto, V. Köhler, C. E. Paul, F. Hollmann and T. R. Ward, ACS Catal., 2016, 6, 3553-3557.

22 M. Bersellini and G. Roelfes, Dalton Trans., 2017, 46, 43254330.

23 M.-P. Cheng, Y.-H. Li, J. Zhou, G.-Q. Jia, S.-M. Lu, Y. Yang and C. Li, Chem. Commun., 2016, 52, 9644-9647.

24 D. F. Sauer, S. Gotzen and J. Okuda, Org. Biomol. Chem., 2016, 14, 9174-9183.

25 M. Hoarau, C. Hureau, E. Gras and P. Faller, Coord. Chem. Rev., 2016, 308, 445-459.

26 C. Marchi-Delapierre, L. Rondot, C. Cavazza and S. Ménage, Isr. J. Chem., 2015, 55, 61-75.

27 T. Heinisch and T. R. Ward, ChemInform, 2015, 46, 34063418.

28 M. Bersellini and G. Roelfes, Org. Biomol. Chem., 2017, 15, 3069-3073.

29 Q. Zhang, X.-X. He, A.-L. Han, Q.-X. Tu, G.-Z. Fang, J.-F. Liu, S. Wang and H.-B. Li, Nanoscale, 2016, 8, 1685-16856.

30 A. Pordea, D. Mathis and T. R. Ward, J. Organomet. Chem., 2009, 694, 930-936.

31 R. Golbedaghi, M. Rezaeivala, M. Khalili, B. Notash and J. Karimi, J. Mol. Struct., 2016, 1125, 144-148.

32 J.-L. Zhang, D. K. Garner, L. Liang, Q. Chen and Y. Lu, Chem. Commun., 2008, 14, 1665-1667.

33 R. Ricoux, M. Allard, R. Dubuc, C. Dupont, J.-D. Maréchalc and J.-P. Mahy, Org. Biomol. Chem., 2009, 7, 3208-3211.

34 Q. Raffy, R. Ricoux and J.-P. Mahy, Tetrahedron Lett., 2008, 49, 1865-1869. 
35 E. Sansiaume-Dagousset, A. Urvoas, K. Chelly, W. Ghattas, J.-D. Maréchal, J.-P. Mahy and R. Ricoux, Dalton Trans., 2014, 43, 8344-8354.

36 J. Tang, F.-P. Huang, Y. Wei, H.-D. Bian, W. Zhang and H. Liang, Dalton Trans., 2016, 45, 8061-8072.

37 P. Subramaniam, S. Anbarasan, S. S. Devi and A. Ramdass, Polyhedron, 2016, 119, 14-22.

38 K. P. Bryliakov and E. P. Talsi, Eur. J. Org. Chem., 2008, 19, 3369-3376.

39 L. Postigo, M. Ventura, T. Cuenca, G. Jimenez and B. Royo, Catal. Sci. Technol., 2015, 5, 320-324.

40 C. Drago, L. Caggiano and R. F. W. Jackson, Angew. Chem., Int. Ed., 2005, 44, 7221-7223.

41 A. Lazar, P. Sharma and A. P. Singh, Microporous Mesoporous Mater., 2013, 170, 331-339.

42 W. Dai, J. Li, B. Chen, G. Li, Y. Lv, L. Wang and S. Gao, Org. Lett., 2013, 15, 5658-5661.

43 H. Srour, J. Jalkh, P. L. Maux, S. Chevance, M. Kobeissi and G. Simonneaux, J. Mol. Catal. A: Chem., 2013, 370, 75-79.

44 J. Legros and C. Bolm, Chem.-Eur. J., 2005, 11, 1086-1092.

45 H. Egami and T. Katsuki, J. Am. Chem. Soc., 2007, 129, 89408941.

46 S. H. A. M. Leenders, R. Gramage-Doria, B. de Bruin and S. Joost, Chem. Soc. Rev., 2015, 44, 433-448.

47 H. Srour, P. L. Maux, S. Chevance and G. Simonneaux, Coord. Chem. Rev., 2013, 257, 3030-3050.

48 J.-P. Mahy, J.-D. Maréchal and R. Ricoux, Chem. Commun., 2015, 51, 2476-2494.

49 D. C. M. Albanese and N. Gaggero, RSC Adv., 2015, 5, 1058810598.

50 A. Mahammed and Z. Gross, J. Am. Chem. Soc., 2005, 127, 2883-2887.

51 Y.-J. Hu, Y. Ou-Yang, Y. Zhang and Y. Liu, Protein J., 2010, 29, 234-241.

52 M. Ohashi, T. Koshiyama, T. Ueno, M. Yanase, H. Fujii and Y. Watanabe, Angew. Chem., Int. Ed., 2003, 42, 1005-1008.

53 R. K. Sharma, A. Pandey and S. Gulati, Polyhedron, 2012, 45, 86-93.

54 C. Herrero, N. Nguyen-Thi, F. Hammerer, F. Banse, D. Gagné, N. Doucet, J. Mahy and R. Ricoux, Catalysts, 2016, 6, 202.

55 N. K. Jana and J. G. Verkade, Org. Lett., 2003, 5, 3787-3790.

56 R. J. Griffin, A. Henderson, N. J. Curtin, A. Echalier, J. A. Endicott, I. R. ardcastle, D. R. Newell, N. E. M. Noble, L. Z. Wang and B. T. Golding, J. Am. Chem. Soc., 2006, 128, 6012-6013.

57 R. S. Varma and K. P. Naicker, Org. Lett., 1999, 1, 189-192.

58 N. Fukuda and T. Ikemoto, J. Org. Chem., 2010, 75, 46294631.

59 S. Lovat, M. Mba, H. C. L. Abbenhuis, D. Vogt, C. Zonta and G. Licini, Inorg. Chem., 2009, 48, 4724-4728.

60 B. Yu, A.-H. Liu, L.-N. He, B. Li, Z.-F. Diao and Y.-N. Li, Green Chem., 2012, 34, 957-962.

61 P. Hanson, R. A. A. J. Hendrickx and J. R. L. Smith, New J. Chem., 2010, 34, 65-84.

62 J. G. W. Gokel, H. M. Gerdes and D. M. Dishong, J. Org. Chem., 1980, 45, 3634-3639.
63 P. G. Reddy, N. Mamidi and C. P. Pradeep, CrystEngComm, 2016, 18, 4272-4276.

64 J. Fujisaki, K. Matsumoto, K. Matsumoto and T. Katsuki, J. Am. Chem. Soc., 2011, 133, 56-61.

65 K. Kamata, T. Hirano, R. Ishimoto and N. Mizuno, Dalton Trans., 2010, 39, 5509-5518.

66 G. La Sorella, L. Sperni, G. Strukul and A. Scarso, Adv. Synth. Catal., 2016, 358, 3443-3449.

67 X.-M. Zhang, J. Tang, L.-N. Wang, D. Yao, Q. Yu, F.-P. Huang and H.-D. Bian, Polyhedron, 2017, 133, 433-440.

68 G. M. Sheldrick, Acta Crystallogr., Sect. A: Found. Crystallogr., 1990, 46, 467-473.

69 G. M. Sheldrick, SHELXS-97, Program for X-ray Crystal Structure Solution, University of Göttingen, Göttingen, Germany, 1997.

70 M. M. Bradford, Anal. Biochem., 1976, 72, 248-254.

71 H. Tang, Z.-H. Shi, N.-G. Li, Y.-P. Tang, Q.-P. Shi, Z.-X. Dong, P.-X. Zhang and J.-A. Duan, Arch. Pharmacal Res., 2015, 38, 1789-1801.

72 Z. Li, H. Yan, G.-L. Chang, M. Hong, J.-M. Dou and M.-J. Niu, J. Photochem. Photobiol., B, 2016, 163, 403-412.

73 G. M. Morris, D. S. Goodsell, R. S. Halliday, R. Huey, W. E. Hart, R. K. Belew and A. J. Olson, J. Comput. Chem., 1998, 19, 1639-1662.

74 J. Gasteiger and M. Marsili, Tetrahedron, 1980, 36, 32193228.

75 R. Tiwari, K. Mahasenan, R. Pavlovicz, C. L. Li and W. Tjarks, J. Chem. Inf. Comput. Sci., 2009, 49, 1581-1589.

76 J.-H. Shi, Y.-Y. Zhu, J. Wang and J. Chen, Luminescence, 2015, 30, 44-52.

77 J.-H. Shi, J. Chen, J. Wang, Y.-Y. Zhu and Q. Wang, Spectrochim. Acta, Part A, 2015, 149, 630-637.

78 J. R. Carey, S. K. Ma, T. D. Pfister, D. K. Garner, H. K. Kim, J. A. Abramite, Z.-L. Wang, Z.-J. Guo and Y. Lu, J. Am. Chem. Soc., 2004, 126, 10812-10813.

79 T. Ueno, T. Koshiyama, S. Abe, N. Yokoi, M. Ohashi, H. Nakajima and Y. Watanabe, J. Organomet. Chem., 2007, 692, 142-147.

80 J.-J. Ao, L. Gao, T. Yuan and G.-F. Jiang, Chemosphere, 2015, 119, 590-600.

81 Y. Teng, L.-Y. Zou, M. Huang and W.-S. Zong, J. Mol. Recognit., 2015, 28, 232-238.

82 Z. Li, H. Yan, G.-L. Chang, M. Hong, J.-M. Dou and M.-J. Niu, J. Photochem. Photobiol., B, 2016, 163, 403-412.

83 J.-H. Shi, Y.-Y. Zhu, J. Wang and J. Chen, Luminescence, 2015, 30, 44-52.

84 L. Rondot, E. Girgenti, F. Oddon, C. Marchi-Delapierre, A. Jorge-Robin and S. Ménage, J. Mol. Catal. A: Chem., 2016, 416, 20-28.

85 J.-L. Zhang, D. K. Garner, L. Liang, Q. Chen and Y. Lu, Chem. Commun., 2008, 14, 1665-1667.

86 P. Rousselot-Pailley, C. Bochot, C. Marchi-Delapierre, A. Jorge-Robin, L. Martin, J. C. Fontecilla-Camps, C. Cavazza and S. Ménage, ChemBioChem, 2009, 10, 545-552.

87 M.-P. Cheng, Y.-H. Li, J. Zhou, G.-Q. Jia, S.-M. Lu, Y. Yang and C. Li, Chem. Commun., 2016, 52, 9644-9647. 
88 A. Mahammed and Z. Gross, J. Am. Chem. Soc., 2005, 127, 90 C. L. Marchena, C. Saux, R. Dinamarca, G. Pecchi and 2883-2887.

L. Pierella, RSC Adv., 2016, 6, 102015-102022.

89 R. Rahimi, A. A. Tehrani, M. A. Fard, B. M. M. Sadegh and 91 L. Rondot, E. Girgenti, F. Oddon, C. Marchi-Delapierre, H. R. Khavasi, Catal. Commun., 2009, 11, 232-235. A. Jorge-Robin and S. Ménage, J. Mol. Catal. A: Chem., 2016, 416, 20-28. 